\title{
PMR Spectra of Poly(methyl vinyl ether) in the Presence of Shift Reagent
}

\author{
Heimei Yuki, Koichi Hatada, Toshihiko Hasegawa, \\ Yoshio Terawaki, and Hiroshi OKuda \\ Department of Chemistry, Faculty of Engineerig Science, \\ Osaka University, Toyonaka, Osaka Japan.
}

(Received February 28, 1972)

\begin{abstract}
KEY WORDS NMR Shift Reagent / Eu(fod) ${ }_{3} /$ Poly(methyl vinyl ether) / PMR Spectrum / Tacticity /
\end{abstract}

Many papers have been published about the lanthanide induced shifts in PMR spectra and their applications to the stereochemical analyses of organic compounds. ${ }^{1-6}$ Recently Katritzky ${ }^{7}$ and Guillet $^{8}$ applied these NMR shift reagents to polymer for the first time and found that the induced shift was dependent upon the tacticity of poly(methyl methacrylate).

This paper reports the successful use of tris(1,1,1,2,2,3,3-heptafluoro-7,7-dimethyl-4, 6-octanedionato)europeum(III) $\left(\mathrm{Eu}(\mathrm{fod})_{3}\right)^{9}$ in the determination of stereoregularity of poly(methyl vinyl ether) (PMVE).

Figure 1 shows the $100-\mathrm{MHz}$ PMR spectra of PMVE in $\mathrm{CCl}_{4}$ at different ratios of $\mathrm{Eu}(\mathrm{fod})_{3}$ to PMVE. The PMVE was obtained in toluene at $-78^{\circ} \mathrm{C}$ by $\mathrm{BF}_{3} \mathrm{OEt}_{2}$ catalyst. All the peaks shifted to the low field upon the addition of $\mathrm{Eu}(\mathrm{fod})_{3}$ and the extent of the shift was in the sequence $\mathrm{CH}>\mathrm{CH}_{2}>\mathrm{OCH}_{3}$. The resolution of the three peaks corresponding to the protons of methoxyl groups in isotactic $(I)$, heterotactic $(H)$ and syn$\operatorname{diotactic}(S)$ triads was also greatly improved by the addition of shift reagent. Moreover, the larger downfield shift for the $\mathrm{CH}$ peak than for the $\mathrm{OCH}_{3}$ peaks allows the methoxyl triads to be observed without interference from the methinyl proton multiplet. Previous attempts to determine the triad tacticity of PMVE from the methoxyl peaks relied on the measurements of the relative peak heights ${ }^{10,11}$ rather than the peak areas. The shift reagent, $\mathrm{Eu}(\mathrm{fod})_{3}$, thus enables one to determine the triad tacticity of PMVE accurately by measuring the areas of methoxyl triad peaks. This successful use of $\mathrm{Eu}(\mathrm{fod})_{3}$ may be due to the non-bulkiness of the side chain in PMVE, which facilitates the coordination of the shift reagent with the ether oxygen.

Fine splitting was observed in the isotactic and heterotactic triad peaks. These must be due to
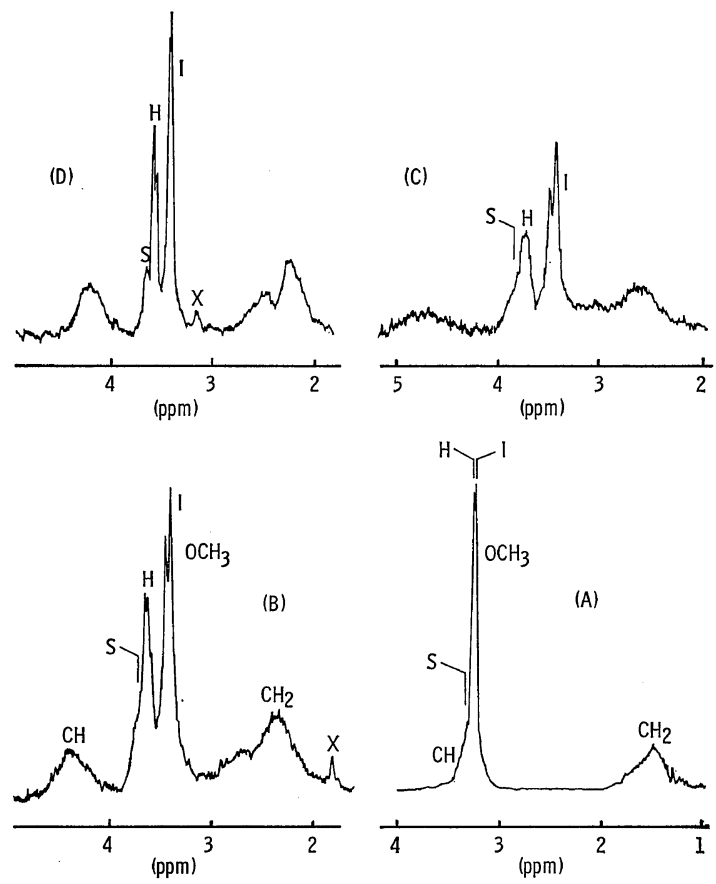

Figure 1. 100-MHz PMR spectra of PMVE in $\mathrm{CCl}_{4}$ in the presence of $\mathrm{Eu}(\text { fod })_{3} . \quad \mathrm{Eu}(\mathrm{fod})_{3} / \mathrm{PMVE}$ : (A) 0.00 ; (B), (D) 0.02 ; (C) 0.03. Temperature: (A), (B), (C) $22.5^{\circ} \mathrm{C}$, and (D) $60^{\circ} \mathrm{C}$. The peak labelled $\mathrm{X}$ is due to the methinyl proton of the shift reagent. 
the pentad structure, which had previously been observed only for methoxyl carbon in the ${ }^{13} \mathrm{C}-\mathrm{NMR}$ spectrum of PMVE. ${ }^{12}$ A detailed investigation of these pentad peaks is now being undertaken. The resolution of these methoxyl proton peaks seemed to be enhanced most at $\mathrm{Eu}(\mathrm{fod})_{3} / \mathrm{PMVE}=0.02$ (Figure 1B). Further addition of $\mathrm{Eu}(\mathrm{fod})_{3}$ decreased the resolution due to the broadening of the peaks (Figure 1C). At higher temperatures the peaks were sharpened up considerably, although the induced shifts were slightly decreased (Figure 1D).

The induced shifts were measured for the triad peaks of methoxyl protons at various ratios of $\mathrm{Eu}$ (fod) $)_{3}$ to PMVE. The results are shown in Figure 2. The downfield shifts increased linearly with increasing ratio and the shift sequence was $S>H>I$. The europium atom must coordinate with the lone-pair electrons on the ether oxygen, and the spectrum must be that of the average of the free and complexed monomer units. It is reasonable to assume that in solution the syndiotactic PMVE chain prefers all-trans zigzag conformation and the isotactic one trans-gauche helical conformation. Then, it can be concluded by the examination of molecular models that the syndiotactic chain places the methoxyl groups in closer proximity to the paramagnetic center of the adjacent monomer unit than the isotactic chain does. Thus it can be assumed that the order of shifts $S>H>I$ is reasonable.

The temperature dependences of the induced shifts of the triad peaks are shown in Figure 3. With an increase in the temperature of the mea-

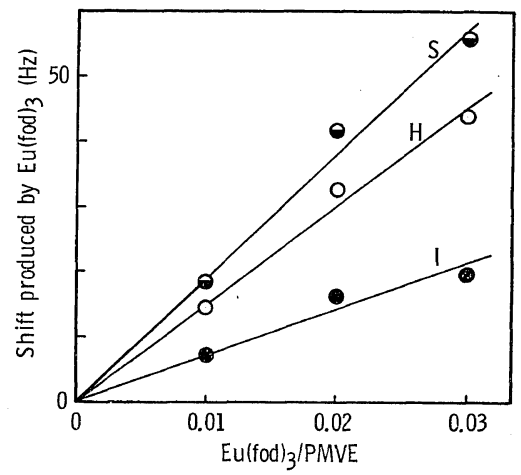

Figure 2. Effect of $\mathrm{Eu}(\mathrm{fod})_{3}$ on the chemical shift of methoxyl protons at $22.5^{\circ} \mathrm{C}$.

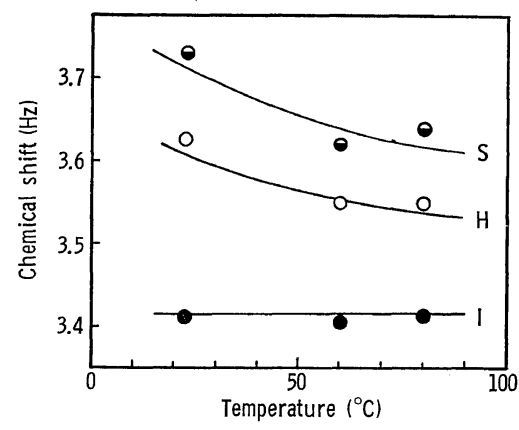

Figure 3. Temperature dependence of chemical shift of methoxyl protons at $\mathrm{Eu}(\mathrm{fod})_{3} / \mathrm{PMVE}=0.02$.

surement the downfield shifts of syndiotactic and heterotactic peaks gradually decreased, while that of isotactic peak was not affected. This may reflect that the conformational change of the polymer chain with change of temperature depends upon the polymer tacticity.

Acknowledgement. The authors are very grateful to Mrs. F, Yano for her clerical assistance in preparing manuscript.

\section{REFERENCES}

1. C. C. Hinckley, J. Amer. Chem. Soc., 91, 5160 (1969).

2. C. C. Hinckley, J. Org. Chem., 35, 2834 (1970).

3. J. K. M. Sanders, D. H. Williams, Chemical Communications, 1970, 422.

4. P. H. Mazzocchi, H. J. Tamburin, G. R. Miller, Tetrahedron Letters, 1971, 1819.

5. M. Ohashi, I. Morishima, T. Yonezawa, Bull. Chem. Soc. Japan, 44, 576 (1971).

6. B. L. Shapiro, J. R. Hlubucek, G. R. Sullivan, L. F. Johnson, J. Amer. Chem. Soc., 93, 3281 (1971).

7. A. R. Katritzky, A. Smith, Tetrahedron Letters, 1971, 1765.

8. J. E. Guillet, I. R. Peat, W. F. Reynolds, Tetrahedron Letters, 1971, 3493.

9. R. E. Rondeau, R. E. Sievers, J. Amer. Chem. Soc., 93, 1522 (1971).

10. S. Brownstein, D. M. Wiles, J. Polym. Sci., Part A, 2, 1901 (1964).

11. K. C. Ramey, N. D. Field, I. Hasegawa, Polymer Letters, 2, 865 (1964).

12. L. F. Johnson, F. Heatley, F. A. Bovey, Macromolecules, 3, 175 (1970). 